\title{
The ancient site of architectural culture origin
}

\author{
Zhihua Xu \\ School of jingdezhen ceramic institute of design art jingdezhen 333403 China
}

Keywords: The ancient, site, architectural, culture origin

Abstract: Jingde town is located in huizhou junction, and adjacent to each other. In history, according to "the huizhou government record" records: "two years in yongtai and analysis of yixian county and rao states the float saddle (note, jingdezhen old once owned by the float saddle county jurisdiction) buy qimen", i.e. the float saddle and subordinate to jingdezhen had and parts belong to huizhou huizhou qimen county jurisdiction. The most important is the main river ChangJiang jingdezhen is originated in qimen county, anhui province, the poyang lake in the Yangtze river, their blood. Jingdezhen and ancient huizhou all belong to the foothills, urban and rural in a small basin surrounded by mountains, around the mountains ring, sceneries in jingdezhen ChangJiang; Compared with xin an river in huizhou. Jiangnan people are unique and exquisite, intelligent for the development and prosperity of the Chinese nation, wrote the magnificent words, part of the hui culture extensive and profound and world-famous jingdezhen ceramics.

1 , the location decision

Jingdezhen lifeline - ChangJiang, comes from anhui qimen, inject the Yangtze river flows through the poyang lake, jingdezhen is connected with a pulse of huizhou. According to the huizhou government record "records:" two years in yongtai and analysis of yixian county and rao states the float saddle JingDeSuo (tang dynasty to the float saddle county jurisdiction) buy qimen [Ding Tingjian (qing dynasty), Lou to fix the: "the huizhou government record", huangshan publishing house, 2010, pp. 53] ", that is to say Jingdezhen had and parts belong to huizhou huizhou qimen county jurisdiction. Jingdezhen and the physiognomy of the ancient huizhou also have many similarities, both hilly topography, the city is located in a basin surrounded by mountains, the mountains surrounding the main magnetic ring, mat ChangJiang water contacted the jingdezhen ceramics handicraft industry is famous for its extensive and profound and business culture of huizhou。

Modern man Wu Ri method has been discussed in the making of huizhou merchants: "my arms surrounded by mountains, in sichuan and the valley, the mountain more and less, in the mountains and open and flat place, is that in a race of people. To reproduce so population, badge to food, from the insufficient for badge to the population of residence, so the business enterprise to rise". According to wanli "increased HuoShi" cloud: "this city the people of the several han a county, the production GuSu cannot supply one percent, Andrew is out and paste in the four parties also." Proverb: "make a living by jia, jia is hopeless; everyone born, everyone do not jia. Also" From the historical literature and folk adage, recognize the contradiction of population and land, forcing HuiZhouRen out with bamboo, wood, tea, charcoal, paint and other local products in return for goods and food, thus forming a long tradition of business. But of huizhou is located in the mountains, are obstruction, traffic inconvenience. Its mountain was blocked, but its water is open, the west by the qimen county under ChangJiang after jingdezhen to poyang lake to the Yangtze 
river, and then to hunan, hubei, guangdong and other places. Thus jingdezhen is HuiZhouRen's westward。

Because of huizhou is located in the mountains, inconvenient transportation problems forced the ancient HuiZhouRen need to the open sea by ChangJiang after jingdezhen to poyang lake to the Yangtze river, and then to hunan, hubei, guangdong and other places with tea, bamboo, lacquer, carbon and other products in return for goods, and food, thus forming a long tradition of business. Jingdezhen is therefore of ancient HuiZhouRen out for commercial trade, the natural geographical environment of jingdezhen and the huizhou cultural exchange has laid a solid foundation for the basic characteristics of jingdezhen ancient huizhou merchants played a major role in the formation and development, first of all, in the history of huizhou merchants and some ceramic porcelain raw materials and ceramic products sales, promote the development of jingdezhen ceramics industry, thus a lot of people from generation to generation of huizhou merchants settled migrated to jingdezhen, will settle must build residence, they formed in huizhou local ideas, customs, aesthetic orientation directly affect the architectural characteristics of jingdezhen. Second, between huizhou and jingdezhen geographically adjacent, the transportation is convenient, so the HuiZhouRen production in jingdezhen porcelain has a lot of, and formed a gang - badge help: established the huizhou hall, hall of the building is built according to the architecture has been gloriously enrolled completely, enough to prove that has been gloriously enrolled on jingdezhen buildings. Third, in the Ming wanli period, the development of Chinese engraving in a rush, printmaking has in-depth to all aspects of the book, the publication almost have the pictures. In the national print works especially in huizhou prints canopy group theory, in history. As a result of huizhou merchants carried, the artistic features of huizhou engravings initially used in ceramic decorations. The aesthetic ideas to later on from the expanded gradually to jingdezhen ceramic decoration, construction decoration. Fourth, jingdezhen as a typical manufacturing city, it should be said is influenced by Confucianism is not inferior to other places. Jingdezhen as the Ming and qing dynasties country because it is over, the seat of the curtain has special geographical advantage, that is jingdezhen zhu xi's hometown -- -- the birthplace of the neo-confucianism is very close to huizhou wuyuan, this causes it to accept to learn the impact of obvious than ordinary place, this influence also in architecture art to reflect 。

2, huizhou merchants and the origin and development of Jingdezhen

Anhui merchants to promote the development of jingdezhen building up huge, outstanding performance in several aspects: first, the history of huizhou merchants in ceramic raw materials and ceramic products sales, and promote the development of jingdezhen ceramics industry, thus a lot of people from generation to generation of huizhou merchants settled migrated to jingdezhen, will settle must build house, them in huizhou local formation of the ideas, customs, aesthetic orientation directly affect the architectural characteristics of jingdezhen. Second, between huizhou and jingdezhen geographically adjacent, the transportation is convenient, so the HuiZhouRen production in jingdezhen porcelain has a lot of, and formed a gang - badge help; Founded the huizhou hall, the hall of the building is built completely according to the architecture has been gloriously enrolled. Huizhou halls are not within the site, but the establishment of huizhou hall proof has been gloriously enrolled on jingdezhen buildings. Huizhou hall xinan yuan, also known as xinan lane that is located in jingdezhen zhongshan road, built in the qing dynasty jiaqing about twenty years (in 1815), jingdezhen is one of the most luxurious hall, rapidly by qimen county, guizhou county, ningxia, and the, jixi, wuyuan hui investment. The whole building, with rich 
full-bodied local characteristics of huizhou. Third, in the Ming wanli period, the development of Chinese engraving in a rush, printmaking has in-depth to all aspects of the book, the publication almost have the pictures. In the national print works especially in huizhou prints canopy group theory, in history. As a result of huizhou merchants carried, the artistic features of huizhou engravings initially used in ceramic decorations. The aesthetic ideas to later on from the expanded gradually to jingdezhen ceramic decoration, construction decoration. [Fang Lili: jingdezhen kilns, people's fine arts publishing house, 2002, p. 121.] Fourth, jingdezhen as a typical manufacturing city, it should be said is influenced by Confucianism is not inferior to other places. Because of jingdezhen as the seat of the national official kilns in the Ming and qing dynasties, has the special geographical advantage, the birthplace of zhu xi's hometown -- -- namely, jingdezhen distance neo-confucianism close to huizhou wuyuan, [note: wuyuan county built about 1200 years of history, belong to the jurisdiction of anhui since ancient times. According to wuyuan county annals, old kai-yuan tang 28 years (AD 740), tang dynasty, wuyuan county, in the eighth day day will be Hugh zhengning county in anhui back jade of township and county leping jinxiang ranks wuyuan county jurisdiction, build county, wuyuan transferred to increased state. Of all the dynasties of song, yuan, Ming and qing generations later, despite increased state belongs to change, but the wuyuan belongs increased state jurisdiction has been no change. Broadcasting song information for three years, increased the state renamed huizhou, therefore, in the history of a mansion of huizhou (increased) six counties (rapidly, ning, wuyuan, qimen county, yixian, jixi) are formed in this way. After the xinhai revolution, waste fu county, wuyuan county directly under the jurisdiction of anhui province. In 1934, Chiang kai-shek government to the need of "communist suppression", in jiangxi had crossed the wuyuan in jiangxi province, the fifth administrative jurisdiction, in 1947 and rowed back to the anhui province seventh administrative jurisdiction. On May 1, 1949, wuyuan liberated. Liberation of wuyuan is the "fields" of the PLA, and liberation as a force of jiangxi province, for military management convenience, at the time and the wuyuan jiangxi reated administration。

3 , has been gloriously enrolled the manifestation of buildings with jingdezhen similarity

First is the similarity of architectural form, has been gloriously enrolled buildings are in the courtyard or put your hands up as the basic form, jingdezhen traditional workshop are mountain by the inner court of the open closed rainy day or courtyard, built a fence courtyard, between is between Ao axis double-box symmetry, these characteristics are similar to building has been gloriously enrolled, is just a slightly different on some construction details. According to literature "country such as star world, every five miles, overlooking a white wall stands: spend their honeymoons. / / tile descaling scales, wedge outstand, ChiWen pull, like guo, extremely full view". It can be seen that the characteristics of huizhou architecture elegant 。

Followed by the similarity of architectural decoration, jingdezhen traditional workshop meet building door frame with engraved masonry, above the door, gate house, water is commonly used in brick, style chic, and decorated with brick. Metope paint grey water. The ground spreads mostly square brick. Building exterior wall in addition to the gate, only a few small window, the window is usually with black or waterproof brick engraved ornament into various forms of tracery, ornament on the wall white. Above the roof gable multi-purpose ladder form, some wall design and grass flexibly. Become one of the important features of jingdezhen traditional workshop buildings 。

Again is the analogy of building structure. Jingdezhen traditional workshop buildings and has 
been gloriously enrolled architecture has the following features: (1) ChuanDouShi architecture, to be born a timber purlin and roof loads directly and spread to the foundation, at the same time with wear fang will fall to the ground from vertical and horizontal directions, upon contact, make it has better bearing space structure system. Step (2) double beams and 3 beam frame, this is the first two kinds of combination of architecture, its characteristic is purlin and ground column. Purlin column before and after the landing, the rest of the columns depending on the needs of the space division every other purlin purlin landing, or two step form double beam or 3 。

Similarity has been gloriously enrolled buildings with jingdezhen ancient site specific performance in the following aspects: the first is the construction pattern of similarity. Huizhou in the Ming and qing architecture. Xu Chengyao in the qing dynasty written by account book about increased idle tan: huizhou "country like the stars, all the five miles, overlooking a white wall, spend their honeymoons. / / tile descaling scales, wedge outstand, ChiWen pull, like guo, extremely full view". Huizhou building layout is characteristic, delicate and elegant residences, grand Hong li ancestral temple, majestic tall arch, is known as the huizhou ancient buildings "quiet". Huizhou architecture is ancient, qingxi, mostly small bridge, flowing water, stone road, square, ancient towers, etc. Thick and strong ancient, thick thick woods, with ancient pavilion, house and pagoda, quiet and beautiful environment. Has been gloriously enrolled buildings generally in the form of courtyard or put your hands up as the basic, and is equipped with the patio, the location of the courtyard can be divided into four types: concave type, type, type, visible narrow patio is the main type of building has been gloriously enrolled. Hospital with a small courtyard. Flat form is square, house is two layers of more, occasionally also has three layers. An enter a door, vestibular regularly patios, both sides is the wing, / for a room downstairs, the left and right sides of two of the main bedroom. The general of the main partition board. Wing width is narrow small, depth is shallow, and better lighting performance。

Jingdezhen ancient site construction of the home plane more introverted square, courtyard building walls, central axis, sta is symmetrical, general layout with around a square courtyard courtyard as the basic unit. These characteristics are similar to building has been gloriously enrolled. Only a slight difference in the characteristics of these details, such as for patios, unlike has been gloriously enrolled patio, jingdezhen ancient site of local-style dwelling houses building courtyard in the middle of the patio is surrounded mostly build pool, pool edges be strong, and decorative pillars, and patio form rectangular square, these are different from the building has been gloriously enrolled patio. Another jingdezhen ancient site construction layout, in the form of a room and into the generally contains two into, also have SanJin, 4 into. Also is mostly the pattern has been gloriously enrolled architecture. Jingdezhen ancient site construction white wall tiles and horsehead walls and has been gloriously enrolled building is consistent. "Horsehead walls" also known as the "wall" screen "firewall" [" horsehead walls "refers to the above two gable roof walls. Village housing intensive fire, wind, in the house with two gable top masonry has a roof above the" fire seal ". The resemblance to the horsehead. Therefore calls "horsehead walls". The construction along with layers of overlapping roof gradient, slope length as the number of files, wall top pick three wire eaves tile, covered with Chinese style tile, and wind deflector shall be fitted at the top of the each buttress head (golden flower board).] A stepwise, coordinated with two slope roof, greatly enrich the contour lines of buildings, give a person with strong appeal. Horsehead walls make a drop for the "three mountains" (mountain flower wall), two fell for "five mountain type" (five tracery wall), even seven tracery wall. Through the change 
of the horsehead walls collocation makes building a resilient, flexible to towering grand and solemn dignified。

The second is the analogy of architectural decoration. Has been gloriously enrolled architectural door cover almost all above the door, gate house, and decorated with brick. Metope paint lime. The ground spreads mostly square brick. In some homes in Ming dynasty, also preserve the prism, month beam, header Gong, wooden partition partition techniques such as the song dynasty. Ancient kiln building signage excellence, art of using saber is fluent, both plump beauty, and do not fall convention (FIG. 2-153). Building exterior wall in addition to the gate, only a few small window, the window is usually with black or waterproof brick engraved ornament into various forms of tracery, ornament on the wall white. Above the roof gable multi-purpose ladder form, some wall design and grass flexibly. Above the door frame with engraved masonry, door cover, gate house, water is commonly used in brick, brick carvings, chic style, become one of the important characteristics of huizhou ancient dwellings houses. Deco railings partition board and engraved look fine. Metope USES lime paint, the ground spreads mostly square brick 。

The third is the construction frame of similarity. Has been gloriously enrolled architectural and jingdezhen ancient site architecture has the following features: 1. The lifting beam frame (FIG. 2-155), in addition to using column supported purlin and directly to the ground, combination TongZhu ridge purlin and other load by the beam before and after the transfer to eaves purlin of the column, the middle connection with fang, forming a space frame system. 2. ChuanDouShi architecture (FIG. 2-156), to be born a timber purlin and roof loads directly and spread to the foundation, at the same time with wear fang will fall to the ground from vertical and horizontal directions, upon contact, make it become the spatial structure system with good stiffness. Step 3. Double beam and 3 beam frame, this is before the combination of the two kinds of structure, its characteristic is purlin and ground column. Purlin column before and after the landing, the rest of the columns depending on the needs of the space division every other purlin purlin landing, or two step form double beam or 3 。

\section{Conclusion:}

To sum up, in the construction pattern of similarity, similarity of architectural decoration and construction frame, on the basis of the similarity of plus wechat business and huizhou scholar to jingdezhen porcelain making, undoubtedly has been gloriously enrolled architectural influence and deep。

References:

1, xiu-mei wu "system of inheritance and change: the republic of China jingdezhen porcelain development research, Beijing: guangming daily press, 2012.

2, various ge armoured with "design art ten speak" jinan: shandong pictorial publishing house, 2006.

3, liang sicheng "Chinese architecture" Beijing: China building industry press, 2005.

4, Dai Wu three "the well after the jinan: shandong pictorial publishing house, 2005.

5, Chang Huaisheng building environment psychology, Beijing: China building industry press, 1990.

6, Liu Duizhen "Chinese ancient architectural history" Beijing: China building press, 2001.

7, lixin li "the design of art research methods" nanjing: jiangsu phoenix publication medium group fine arts publishing house, 2010。

zhihua $\mathrm{xu}$, male, PhD, postdoctoral fellow, university of jingdezhen ceramics backbone 
teachers, research direction: environmental art design and theoretical study, environmental ceramic art, the Chinese stone inscription art history research. This fund projects: 1 , jiangxi social sciences planning project of the intangible cultural heritage tourism landscape design research jingdezhen ancient kiln heritage tourism landscape, for example, the number is: 15 ys27. 2, in jiangxi province cultural department scientific research project of the jingdezhen culture industry construction under the ancient site of the landscape design research, number is: YG2014177. 3, humanities and social science in colleges and universities in jiangxi province project the regionality of humanities landscape design - to jingdezhen ancient kiln building landscape design as an example, and Numbers for: GX201529 